\title{
ENGINEERING LEADERS RETAIN THEIR TECHNICAL IDENTITIES: LIVING THE SOCIOTECHNICAL DUALITY
}

\author{
Andrea Chan ${ }^{2}$, Cindy Rottmann ${ }^{2}$, Doug Reeve ${ }^{1,2}$, Emily Moore $^{1,2}$, Milan Maljkovic $^{2}$, Emily Macdonald- \\ Roach $^{1,2}$ \\ ${ }^{l}$ Department of Chemical Engineering \& Applied Chemistry \\ ${ }^{2}$ Troost Institute for Leadership Education in Engineering (Troost ILead) \\ Faculty of Applied Science and Engineering, University of Toronto \\ AndreaNW.Chan@utoronto.ca
}

\begin{abstract}
In this qualitative study, we investigate the ways engineering leaders across different industry sectors conceive of their own professional identities, including those who work in less engineering-intensive sectors such as financial and public services. Our findings are consistent with previous research that rejects a dichotomizing of engineering identity into distinct technical and social dimensions along technical and managerial career paths [4], [11]. Drawing directly from the experiences of 29 engineering leaders, our results suggest that engineers in management and leadership, even those outside of traditional engineering industry sectors, retain technical dimensions of their professional identities. By challenging the assumption that engineers must abandon their technical identities in order to embrace leadership work, findings of this study can demonstrate to students and early career engineers they need not resist leadership for fear of losing their engineering identities.
\end{abstract}

Keywords: Engineering identity; Engineering leadership; Situated learning theory; Career paths

\section{INTRODUCTION}

\subsection{Statement of the Problem}

The concept of identity has an important place within engineering education. Researchers have explored the importance of identity in relation to entry and persistence in engineering undergraduate programs [5], [14]. Engineering student identities have also been found to be influential on career paths post-graduation [15]. From research that attempts to understand engineering as a leadership profession, it appears there are various leadership orientations that engineers adopt, each anchored by different but equally authentic engineering identity features (e.g., technical expert, collaborative optimizer, organizational innovator) [11]. Our paper contributes to the growing body of research in support of the notion that engineering leadership identities are fluid, multifaceted,

\footnotetext{
${ }^{1}$ Heterogeneous Engineering, coined by John Law [7], refers to an understanding that networks/systems/worlds are built in ways that are
}

socially realized, and practice-informed. More specifically, it challenges a socially constructed and gendered dichotomy, a technical-social cleavage within engineering, that suggests "[a]t the core of engineers' identities and engineering practice lies a sense of the technical which specifically excludes the social" [3]. This problematic assumption has further lent itself to the belief that a "move into management [is] a move away from engineering" [4]. If leadership is understood primarily as the 'management' of people, it stands to reason that many engineers do not identify with leadership as they view it in conflict with their professional (technical) identity [11], [13].

\subsection{Literature Review}

Critics of the technical-social split and the internalization of it by engineers and industry have examined the implications from varying perspectives. Researchers examining the organization of work have pointed to the shortcomings of the "dual-career ladder" model of advancement, an organizational arrangement conceived around the mid-twentieth-century by firms as a way of offering engineers who do not wish to climb the managerial corporate ladder an alternative path, a technical ladder of advancement, that would allow them to retain highly-skilled technical professionals [1], [10]. But this arrangement proved unsatisfactory for many. Within the occupational culture of engineering, there is what Cardador calls the "inverted hierarchy" [2], where technical/design work is often perceived to be more valuable and respected than social/managerial work [1], [3]. However, management positions, especially at the senior level, are associated with greater financial rewards, organizational authority, and social standing in the context of normative western cultural values [1], [10]. Even at the conceptual level, the model (predicated on a split between the technicist and heterogenous ${ }^{1} /$ sociotechnical identities) suggests both paths require some level of sacrifice by

mediated by existing social, natural, and physical conditions, all of which are interrelated. 
engineers (i.e., occupational standing and identity versus financial reward and broader social prestige).

For decades, empirical studies have pointed to the limitations of this dual track model [1], [9], [12], as this arrangement does not speak to the diversity of professional orientations, values, and interests across the profession. Research has found that engineers in large proportion, and with some correlation to age, prefer exciting and challenging work over either mode of advancement/reward system [1]. Further, having challenging work and intrinsic work interest were found to predict engineers' job satisfaction across different typologies of personal work values. The finding holds true not only for those who held either technically oriented or managerially oriented values, but also for others who highly value both technical and managerial work goals, even some who only moderately valued both [17]. Not only do engineers as a group have wide-ranging values and aspirations, current research suggests they chart career paths far beyond the two tracks [16], and these career paths (even for technical specialists) can assume both technical and social/managerial/leadership dimensions [12].

But the power to chart career paths are not entirely our own, and our identity comes not only through how we see ourselves but also how we are seen by others, all of which are socially negotiated and mediated by our social location. Faulkner refers to the hierarchy in engineering that privileges the technical (instrumental/logical/specialist) above the social (relational/emotional/heterogeneous) as one that is deeply gendered. Using ethnographic research methods, Faulkner finds most engineers "oscillate between or straddle, not always comfortably, [both] technicist and heterogeneous engineering identities," and that the technical-social relationship is not a mutually exclusive dichotomy but instead a "dualism" encompassed within the core of good engineering work [4].

But despite this sociotechnical reality in the practice of all engineering, the dominance of the technicist identities endures for both men and women because, in a profession largely represented by men, technicist identities align with traditional notions of masculinity, which can undermine women's sense of belonging to the profession and identification (from self and others) as being 'real' engineers.

Ultimately, Faulkner calls on the engineering profession to promote and "celebrate heterogenous understandings of engineering and heterogeneous engineering identities," because good engineering requires the true integration of the technical with the social, and embracing and showcasing heterogenous identities in engineering is vital for attracting people with a wide range of talent and interests, and for "creat(ing) space for a more diverse range of people to become engineers" [4]. We consider this research a response to this call; we explore, and generate exposure for, the heterogenous identities of engineering leaders from diverse industry sectors.

\subsection{Theoretical framework}

The theoretical foundation grounding this paper and the larger project is Lave and Wenger's situated learning theory [8], which presents learning as a socio-cultural, practice-embedded phenomenon. This theory offers us a point of departure, that learning is part of an "identitymaking life project," carried out through everyday activities and social interaction within communities of practice (i.e., team, organization, profession). It emphasizes learning and identity development that is embedded within practice, beginning through the process of "legitimate peripheral participation" of new community members through active engagement in continuously changing practices in ever-changing communities. The interconnections between practice, learning, and identity as they relate to engineering leadership, and the contextspecific and fluid nature of these social processes, serve as the analytical lens through which we seek to understand engineering leadership identities.

Although all our participants held formal (senior) management positions, in this study we interpret leadership not as positional but as a social/relational process "of people working together to accomplish change or to make a difference that will benefit the common good" [6]. This concept shifts the emphasis within leadership away from the individual and onto the situated relational dynamics of a group. Situated learning theory, then, lends well to the study of engineering leadership as a social/relational, identity making process.

\subsection{Research Question}

How do seasoned engineering leaders understand their professional identities?

\section{Method}

\subsection{Data collection and participant sample}

As part of our larger engineering leadership project, data were gathered through in-depth career-history interviews with engineering leaders with at least 25 years of work experience [12]. Through referrals from several key informants, we recruited 29 participants who held senior positions belonging to 9 industry sectors, including more traditional ones such as chemical processing, manufacturing, and consulting, as well as less traditional sectors such as public service and financial services.

Although we attempted to recruit for demographic diversity, our final sample was $71 \%$ male and $79 \%$ white, with a mean age of 58. Sixty-one percent had completed a graduate degree. Even with only $29 \%$ women in the group, the proportion of women in our sample exceeds the $14 \%$ of women engineers in Canada in 2019 (Engineers Canada, 2020). 
The semi-structured interviews lasted between one and a half to two hours each. They were audio recorded and later transcribed verbatim for data analysis.

\subsection{Data analysis}

Our multidisciplinary research team explored the 29 individual narratives to examine for themes shared along and across five distinct career paths. These career paths emerged as part of the initial analysis of the interview data, and we identified them as: Company Men; Boundary Spanners, Technical specialists, Invisible engineers; and Entrepreneurs. Summary details of the career paths are presented below, and full details can be found in [12].

For this paper, each member of the research team coded transcripts belonging to a different career path. As part of the larger project, each transcript had been reviewed by at least two members of the team, and as such, we were able to affirm/question the coding interpretations of others as part of our analytical process when we met as a group. The initial coding process was largely inductive, and in sorting the codes we incorporated theory to help interpret and categorize the themes that emerged.

Table 1: Five Engineering Career Paths

\section{Career Path Composite Description of Identity} and Path

\begin{tabular}{|c|c|}
\hline $\begin{array}{l}\text { Company } \\
\text { Men }(n=5)\end{array}$ & $\begin{array}{l}\text { Identity tightly intertwined with that of } \\
\text { their organizations where they spent the } \\
\text { better part of their career; Groomed } \\
\text { into senior positions; Lead by driving } \\
\text { themselves and others to win. }\end{array}$ \\
\hline $\begin{array}{l}\text { Technical } \\
\text { Specialists } \\
(n=6)\end{array}$ & $\begin{array}{l}\text { Employ technical acuity to solve } \\
\text { complex problems in engineering- } \\
\text { intensive organizations; Do not } \\
\text { necessarily identify with the title of } \\
\text { "leader" but are aware of the need to } \\
\text { influence others as they advance in } \\
\text { their career }\end{array}$ \\
\hline $\begin{array}{l}\text { Boundary } \\
\text { Spanners } \\
(n=5)\end{array}$ & $\begin{array}{l}\text { Senior leaders with integrative } \\
\text { functions; Often called in to mediate } \\
\text { challenging, emotionally charged } \\
\text { situations; Connector and mobilizer of } \\
\text { people and information across sectors, } \\
\text { industries, departments, and national } \\
\text { contexts to solve complex problems } \\
\text { and drive organizational learning/ } \\
\text { success/change }\end{array}$ \\
\hline $\begin{array}{l}\text { Entrepreneurs } \\
(n=6)\end{array}$ & $\begin{array}{l}\text { Leapt to better prospects, driven by } \\
\text { technical curiosity or having } \\
\text { encountered barriers to growth and } \\
\text { success in traditional bureaucratic } \\
\text { organizations }\end{array}$ \\
\hline $\begin{array}{l}\text { Invisible } \\
\text { Engineers } \\
(\mathrm{n}=7)\end{array}$ & $\begin{array}{l}\text { Identify strongly with engineering roots } \\
\text { although not in traditional engineering } \\
\text { role; Utilize technical training and } \\
\text { adaptive communication skills to }\end{array}$ \\
\hline
\end{tabular}

lead/influence multi-stakeholders in (para-)public service and financial services

\section{FINDINGS}

Three major themes related to engineering identities emerged when we explored the experiences of the 29 participants collectively. We also noted nuanced differences between career paths, which we considered under each individual theme.

\subsection{Living the sociotechnical duality}

By and large, the participants spoke of having come to a technically oriented identity early on in childhood (e.g., tinkerer, maker/builder) and had displayed early talent for science and mathematics. Often, they described other identities associated with a technical orientation (e.g., disciplined, analytical) but also ones that play to both technical and social orientations (e.g., problem solver, innovator). While they may no longer do 'hands-on' technical work, they retained their technical identity because it is part and parcel of their leadership work (i.e., part of the sociotechnical duality).

\section{...there's got to be a technical piece if we're talking about engineering leaders...technical depth and confidence. (Melissa, Consulting, 3055-3060).}

I guess that's one thing I would say about my career is I always feel myself half in a technical world, and half in a human impact world. Which I think is why I was so fascinated with human factors to begin with. But now, I know I have to spend more time not worrying about the technical stuff, but worrying about how the technical stuff impacts the people involved. (Amy, Financial Services, 1065-1069).

Technical Specialists were most likely to resist the label of 'leader', although they understood fully that they serve a leadership function and recognized the importance of influencing others.

\section{I really don't look at myself as being a leader. I look at myself more of technical person, as problem solver...[But] to fix technical problems, you also need somehow to drag people along with you and so you've got to be able to convince people that what ... I had to convince people that what I do is interesting and important enough for them to put in an effort for me. (Paul, Higher Education, 831-854)}

Although collectively, most were at ease with the ways in which they integrated their technically and socially oriented selves in their engineering leadership work, one person in particular expressed her struggle stemming from 
how other engineers perceived her, not only because of her non-technical role, but also because she worked in an industry sector not traditionally associated with engineering (i.e. Financial Services).

"For me, it was also the bias [from others]...I'm an engineer, but am I really? Identity crisis. ” (Donna,

Financial Services, 636)

Her internal identity crisis was momentary, but she described continued frustration with peers, who at engineering conferences would "walk away" from her because they no longer see her as an engineer and can no longer identify with her.

I'm still pushing [against] the unconscious bias, or rather conscious bias that they have against engineers ... who are not working in the traditional roles. I'm trying to change the mindset, ... because [when] you've taken engineering, there's so many things you can do, not just design cars, and parts, and piping. (483-487)

I think I need to find a way to help foster that conversation... Make a connection for them, so that they can see how it's interesting, or how it relates to what they do. (645-648)

Donna's experience speaks to the way our identity is more than how we see ourselves. Although she has deep attachment to her engineering identity, the way others see her is a threat to her sense of self and can undermine her sense of belonging to the engineering profession - both of which she actively resists.

\subsection{Identity is fluid, not static}

Donna's experience above illustrates the way our identities are realized/upheld/challenged through our interactions with other members in our communities of practice.

Unlike their technical identities, only a few participants came to their leadership identity in childhood or early adolescence (e.g., through sports, science competition, student council). For others, leadership identity was realized much later, by 'doing' engineering leadership. "I didn't ever envision being a leader," said Marian (1015), but she recognized that others at her firm saw her as one.

I think leadership, for me, happens- happened when-I started to realize that people kept coming to me-for-for advice. Like, all the time-... seniors and juniors alike" (780-781)...Technical or- HR or commercial, or personal and I try to help them. That's what I do. I look after problems" (Marian, Consulting, 1790-2036).

Like Donna, the way Marian identifies her professional self is influenced by the way others see her. How the participants came to see themselves as leaders, and the type of leaders they are, evolved through different professional experiences over time. As such, aspects of identity can vacillate depending on circumstances and points in time. For example, leadership identity can be shaken after a setback. Steve described the impact of a professional struggle he experienced,

I'd say largely that it really made me question if I wanted to be in a leadership role anymore (Steve, Chemical Processing, 772).

But leadership identity can just as easily be reinvigorated by a win. Speaking of a subsequent proud moment he had,

[It] reignited some of the passion I had before about seeking and influencing change. Probably got me back into a leadership type of mindset... (920-921)

Identity is not static. It is learned and relearned or maintained through lifelong experiences, in response to external situations and context.

\subsection{Gendered identities in engineering leadership}

The most prominent way gender manifested in the discussion of identity was that it was only ever mentioned explicitly by the women we interviewed, particularly in relation to how they were perceived by others. For some, there is an acute awareness that they are not just leaders, but 'women in leadership', and that has implications on the way in which they (can) lead.

\footnotetext{
"... [they say], "Oh you're really good. You listen to everybody, but you don't shy away from making a decision." But I couldn't make a decision without listening to everybody. That wouldn't work for me. Whereas, I think a guy wouldn't have to maybe entertain everybody's ideas as much." (Amy, Financial Services 1185-1190)
}

Leadership is learned, internalized, and enacted differently, often along lines of gender. For Amy, the situated learning occurred through comparisons of how she saw men and women lead, and her conclusion was that her leadership approach had to conform to gendered expectations to be effective (i.e., less directive and more collaborative/conciliatory). Another example of identity formation through situated learning comes from Marian, who came to identify as a leader through recognition that others look to her for guidance (on work and non-workrelated matters). There is emphasis again on dimensions of leadership that align with gender stereotypes (e.g., caretaking and support). 
Although Donna's experience of skepticism from other engineers is not representative of the whole group, it is worth noting that the most explicit narrative of a leader having her engineering identity challenged by others comes from a racialized woman on a non-traditional ('Invisible Engineers') career path. Her experience brings to life Faulkner's claim, that having a narrow definition of engineering can have a disproportionately negative and exclusionary effect on those underrepresented in engineering [4].

\section{DISCUSSION}

\subsection{Implications}

In our study, not only did we uncover an array of heterogeneous engineering leadership identities, we found that the process by which engineering leaders come to their identities is also heterogeneous. Employing situated learning theory as a conceptual lens, we were reminded that identity development occurs in context-specific ways and is an ongoing process.

The balancing act of holding integrated technical/social identities weighed differently on different engineering leaders. For the most part, engineering leaders retained their technical identities, as they continue to draw on their technical training in their leadership work, even if they are far removed from any 'hands-on' technical work. But just because the engineering leaders we interviewed held more heterogenous understanding of engineering as a result of their own career experiences, the assumption cannot be made that the profession as a whole has the same expanded view. Furthermore, our findings also revealed that for certain women engineering leaders, their identity work was clearly mediated by their gender.

Altogether, our findings speak to the possibilities for the profession and the work that still needs to be done. Engineering students and early career engineers can find inspirations in the non-traditional and less visible career possibilities demonstrated through the varied career paths of engineering leaders. They can also find some reassurance that engineers with a wide range professional and leadership identities can find success (i.e., there is no one engineering (leadership) identity). But as one of the study participants (Donna) pointed out, there need to be further conversations within the profession to help recognize and (in Faulkner's words) "celebrate heterogenous understandings of engineering and heterogenous engineering identities" [4]. Also important are conversations on the way inherent biases can impact on the engineering leadership identities and leadership work of members of underrepresented groups. Raising awareness with the new generation of engineering students would be a good place to begin.

\subsection{Limitations}

Although we were attentive to gender in our analysis, our limited sample prevented us from interpreting our findings in any intersectional way that also considered race, immigrant status, and other socially constructed categories of difference. We should note also that we were only able to consider gender as binary when it should be considered on a spectrum. To achieve a more inclusive understanding of the identities of all engineering leaders, future research needs to ensure greater representation from the underrepresented groups whose voices are missing from this study.

\section{CONCLUSION}

The findings of our study reinforce the interconnectedness of the technical-social dimensions at the heart of engineering work, especially engineering leadership work. Broadly, engineering leaders retained their passion for the technical aspects of engineering while expanding the scope of their expertise in vastly different areas. Although their identities are reinforced by their personal passion and the technical knowledge required in their day-to-day leadership work, identities are also subject to influence from others who may view them differently. Greater exposure of a heterogenous understanding of engineering within the profession can help align how engineering leaders see themselves and how they are seen by others.

\section{Acknowledgement}

For their support to this research, we would like to thank the industry partners of the Troost ILead Community of Practice and the Dean's Strategic Fund (Faculty of Applied Science and Engineering, University of Toronto). We are grateful to the 29 engineering leaders who generously shared their stories and wisdom with us.

All procedures performed in this study involving human participants were in accordance with the ethical standards of the University of Toronto Research Ethics Board, per protocol \# 00027770.

\section{References}

[1] Thomas J. Allen and Ralph Katz, "The dual ladder: motivational solution or managerial delusion?" $R \& D$ Management, vol. 16, no. 2, pp. 185-197, April 1986, doi: 10.1111/j.1467-9310.1986.tb01171.x.

[2] M. Teresa Cardador, "Promoted Up But Also Out? The Unintended Consequences of Increasing Women's Representation in Managerial Roles in Engineering," Organization Science, vol. 28, no. 4, pp. 597-617, August 2017, doi: 10.1287/orsc.2017.1132. 
[3] Wendy Faulkner, "Dualisms, Hierarchies and Gender in Engineering," Soc Stud Sci, vol. 30, no. 5, pp. 759-792, October 2000, doi: 10.1177/030631200030005005.

[4] Wendy Faulkner, "Nuts and Bolts and People': GenderTroubled Engineering Identities," Soc Stud Sci, vol. 37, no. 3, pp. 331-356, Jun. 2007, doi: 10.1177/0306312706072175.

[5] Allison Godwin, Geoff Potvin, Zahra Hazari, and Robynne Lock, "Identity, Critical Agency, and Engineering: An Affective Model for Predicting Engineering as a Career Choice: Identity, Critical Agency, and Engineering Careers," J. Eng. Educ., vol. 105, no. 2, pp. 312-340, Apr. 2016, doi: 10.1002/jee.20118.

[6] Susan R. Komives, Nance Lucas, and Timothy R. McMahon, Exploring Leadership: For college students who want to make a difference. San Francisco, CA: Jossey-Bass, 1998.

[7] John Law, "On the Social Explanation of Technical Change: The Case of the Portuguese Maritime Expansion," Technology and Culture, vol. 28, no. 2, pp. 227-252, April 1987, doi:10.2307/3105566

[8] Jean Lave and Etienne Wenger, Situated learning: Legitimate peripheral participation. Cambridge: Cambridge University Press, 1991, doi: 10.1017/CBO9780511815355

[9] Paul D. McKinnon, "Steady-State People: A Third Career Orientation," Research Management, vol. 30, no. 1, pp. 2632, January 1987, doi: 10.1080/00345334.1987.11757012.

[10] Karen Roberts and Jeff Biddle, "The transition into management by scientists and engineers: A misallocation or efficient use of human resources?" Hum. Resour. Manage., vol. 33, no. 4, pp. 561-579, 1994, doi: 10.1002/hrm.3930330406.

[11] Cindy Rottmann, Robin Sacks, and Doug Reeve, "Engineering leadership: Grounding leadership theory in engineers' professional identities," Leadership, vol. 11, no. 3, pp. 351-373, August 2015, doi: $10.1177 / 1742715014543581$.
[12] Cindy Rottmann, Doug Reeve, Serhiy Kovalchuk, Mike Klassen, Milan Maljkovic, and Emily L. Moore, "Counting Past Two: Engineers' Leadership Learning Trajectories," in Proc. 2019 American Society of Engineering Education ASEE Annual Conference \& Exposition, (Tampa, FL; 16-19 June 2019), Available from https://www.asee.org/public/conferences/140/papers/25598 /view

[13] William J. Schell, Bryce E. Hughes, and Brett Tallman, "Exploring the Conflict Between an Engineering Identity and Leadership," in Proc. CEEA Canadian Engineering Education Association Conf., CEEA-ACEG18, (Vancouver, BC; 3-6 June 2018), 7pp., 2018, doi: 10.24908/pceea.v0i0.13100.

[14] Cicely Striolo, Michaela Pollock, and Allison Godwin, "Staying or leaving: contributing factors for U.K. engineering students' decisions to pursue careers in engineering industry," European Journal of Engineering Education, pp. 1-25, January 2020, doi: 10.1080/03043797.2020.1711707

[15] Karen L. Tonso, "Student Engineers and Engineer Identity: Campus Engineer Identities as Figured World," Cult.Scie.Edu., vol. 1, no. 2, pp. 273-307, September 2006, doi: 10.1007/s11422-005-9009-2

[16] Michel Tremblay, Thierry Wils, and Caroline Proulx, "Determinants of career path preferences among Canadian engineers," J. Eng. Technol. Manage., vol. 19, no. 1, pp. 123, 2002.

[17] James M. Watson and Peter F. Meiksins, "What Do Engineers Want? Work Values, Job Rewards, and Job Satisfaction," Science, Technology, \& Human Values, vol. 16, no. 2, pp. 140-172, April 1991, doi: $10.1177 / 016224399101600202$ 